\title{
Ross Syndrome - A Rare Disorder of Sweating, Areflexia, and Tonic Pupil
}

\author{
Vijayakumar S. ${ }^{1}$, Dhara Varun², Balasubramaniyam Booptathy ${ }^{3}$, Dinesh Raghav ${ }^{4}$
}

\begin{abstract}
${ }^{1}$ Department of Dermatology, Venereology and Leprosy, Shri Sathyasai Medical College and Research Institute, Sri Balaji Vidyapeeth, Ammapettai, Tamilnadu, India. ${ }^{2}$ Department of General Medicine, Shri Sathyasai Medical College and Research Institute, Sri Balaji Vidyapeeth, Ammapettai, Tamilnadu, India. ${ }^{3}$ Department of General Medicine, Shri Sathyasai Medical College and Research Institute, Sri Balaji Vidyapeeth, Ammapettai, Tamilnadu, India. ${ }^{4}$ Department of General Medicine, Shri Sathyasai Medical College and Research Institute, Sri Balaji Vidyapeeth, Ammapettai, Tamilnadu, India.
\end{abstract}

\section{INTRODUCTION}

Sweating is a physiological process that is essential to maintain the temperature of the human body. Any derangement with this process leads to not only physical disturbances but can also cause psychological and social disturbances. Localized hyperhidrosis can have many causes. It can be a normal physiological response to local heat and pressure or it may be secondary to some pathological conditions causing local vasomotor disturbances (peripheral neuropathy or spinal injury) or sometimes it's secondary to neurological problems like tumour, inflammation and damage affecting the central nervous system, autoimmunity, viral infections and genetic disorders. Classically, Ross syndrome was described in 1958; it is a triad of Adie's pupil, areflexia and segmental hypohidrosis or anhidrosis. ${ }^{1}$ Anhidrosis is secondary to damage to the postganglionic cholinergic fibres that supply the sweat glands and in compensation, to the absent sweating in the affected segments there is over sweating elsewhere. ${ }^{2}$ Most of the times it is this excessive sweating that bothers the patient the most, in our case report we describe a patient who had excessive sweating over the left trunk and left lower limb which was, in fact, anhidrosis on the opposite side.

Ross syndrome is a rare entity, (defined a clinical trial of segmental anhidrosis or hypohidrosis, areflexia, and atonic pupil. It is a progressive and complex disorder of Thermoregulation. The first component of the triad defines Harlequin syndrome and the last two defines Holmes-Adie syndrome). Ross syndrome has an unpredictable course. Usually, it presents with the absence of sweating in a particular area of the body which causes heat intolerance to the patient. There are only a few cases in the literature, here we present to you a case of Ross syndrome presenting with hyperhidrosis on the left side of the trunk and left lower limb. We intend this case report to inform academics and clinicians of various modalities about this entity, especially to the dermatologists, physicians and neurologists as patients usually present with this complex disorder to them.
Corresponding Author: Vijayakumar $S$, F11, B-Block, ICIPL Amaro, Patturoja Street, Kavya Gardens, Manapakkam, Chennai, Tamilnadu, India.

E-mail: vijaykumarderm@gmail.com

DOI: $10.14260 / j e m d s / 2020 / 521$

How to Cite This Article:

Vijayakumar S, Varun D, Booptathy B, et al. Ross syndrome- a rare disorder of sweating, areflexia, and tonic pupil. J Evolution Med Dent Sci 2020;9(33):2400-2402, DOI: $10.14260 / \mathrm{jemds} / 2020 / 521$

Submission 15-05-2020,

Peer Review 07-07-2020,

Acceptance 14-07-2020,

Published 17-08-2020.

Copyright (C) 2020 JEMDS. This is an open access article distributed under Creative Commons Attribution License [Attribution 4.0 International (CC BY 4.0)] 


\section{PRESENTATION OF CASE}

A 35-year-old male patient presented with complaints of excessive sweating of the right trunk and right lower limb (from the upper thigh to the foot) lasting for 5 years which is worse during summer and was associated with anhidrosis over the face, left side chest, abdomen and left upper limb. He had a history of a fall from a two-wheeler 10 years ago which caused laceration to the left ear but had no neurological symptoms before or after the fall (post-fall he was admitted and tested, but had no neurological abnormalities clinically or radiologically). He had no history of previous stroke or TIA, no history of any sexually transmitted diseases, no history of any rheumatological disease or an autoimmune disease of any sort. On admission to the medical ward, we did his neurological examination along with other systems. It had 3 positive findings. ${ }^{1}$ excessive sweating on the right side of the body from $\mathrm{T} 7$ to $\mathrm{T} 1$ and from the inguinal ligament to the foot. ${ }^{2}$ Hypohidrosis on the face, left side chest, abdomen and left upper limb. ${ }^{3}$ Pupillary examination showed anisocoria, with the right pupil larger than the Left side-eye has normal pupil. Pupil of right eye reacted sluggishly to light (Adie's tonic pupil) and on adding $0.125 \%$ pilocarpine drops, there was a constriction in the right pupil (pilocarpine test). Accommodation reflex, visual acuity and fundus examination on both eyes were normal. ${ }^{4}$. All the deep tendon reflexes were absent other than the mentioned findings neurological examination was normal, other systems examination was also normal. Blood Investigations revealed no abnormalities (RBS, ESR, CBC, Serum electrolytes, RFT and LFT), chest x-ray was normal, ultrasound abdomen was normal, MRI brain and spine revealed no neuro parenchymal abnormalities, ECG and 24 hour Holter monitoring had no abnormalities, antinuclear antibody test was negative, VDRL and serology for HIV, HEP-B and HCV were negative, Thyroid function test was within normal limits and anti-thyroid antibodies were negative. Upon performing sweat test using rice starch and iodine his left trunk did not show any colour change whereas the right side showed a colour change from cream to dark blue from right side T7 to T1. Patient didn't give consent to do the starch test over the legs. Skin Biopsy on the right lumbar region (hyperhidrosis side) showed lining by stratified squamous epithelium with underlying tissue showing an increase in the number of eccrine glands. Skin Biopsy done from the left lumbar region showed lining by stratified squamous epithelium with a scanty/reduced number of eccrine glands.

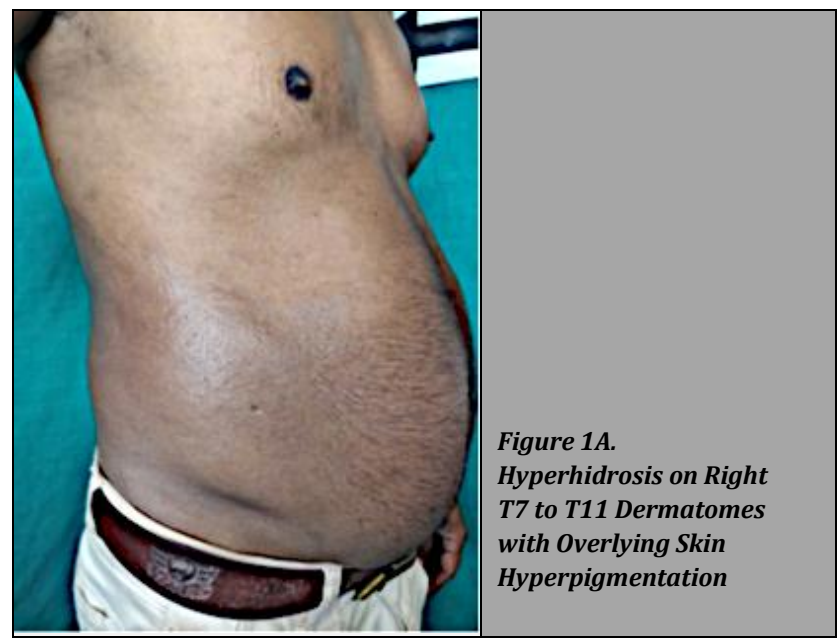

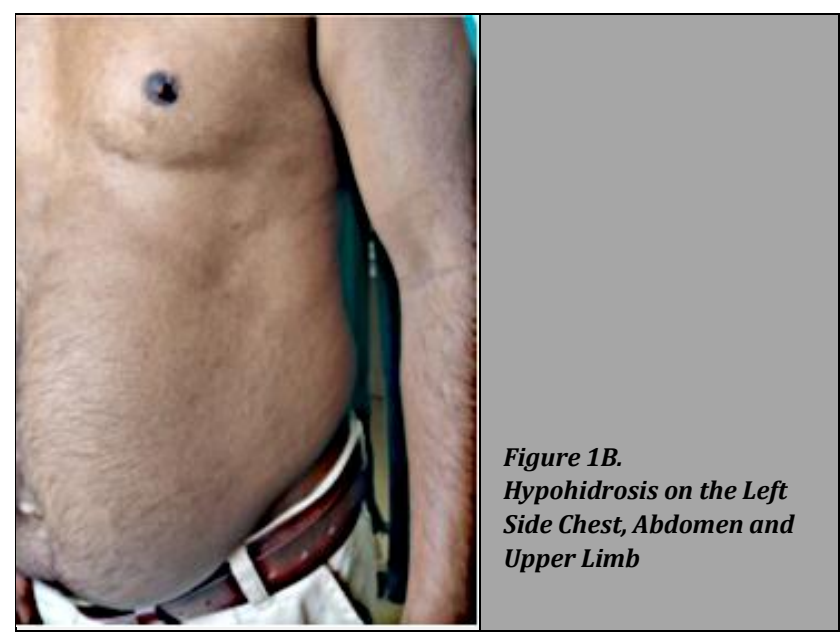
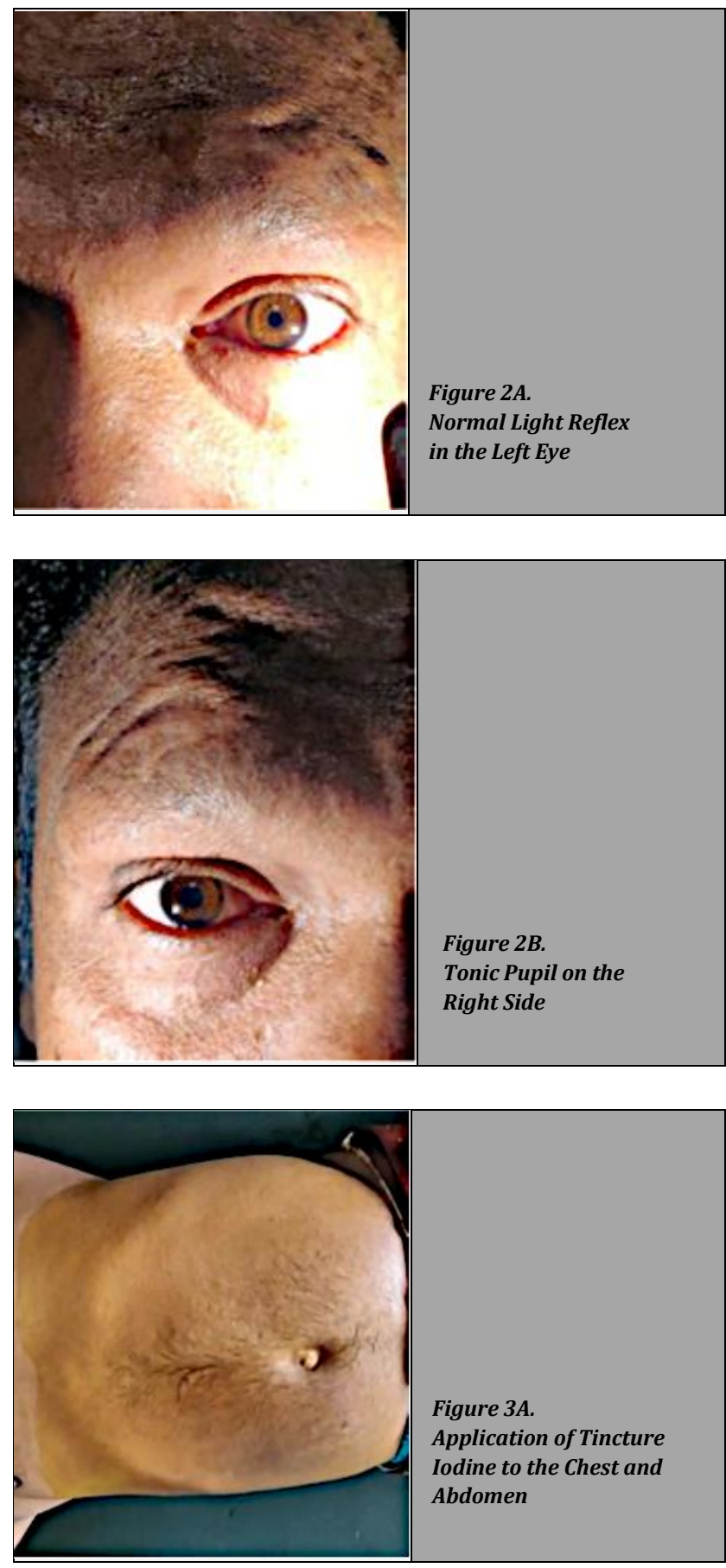

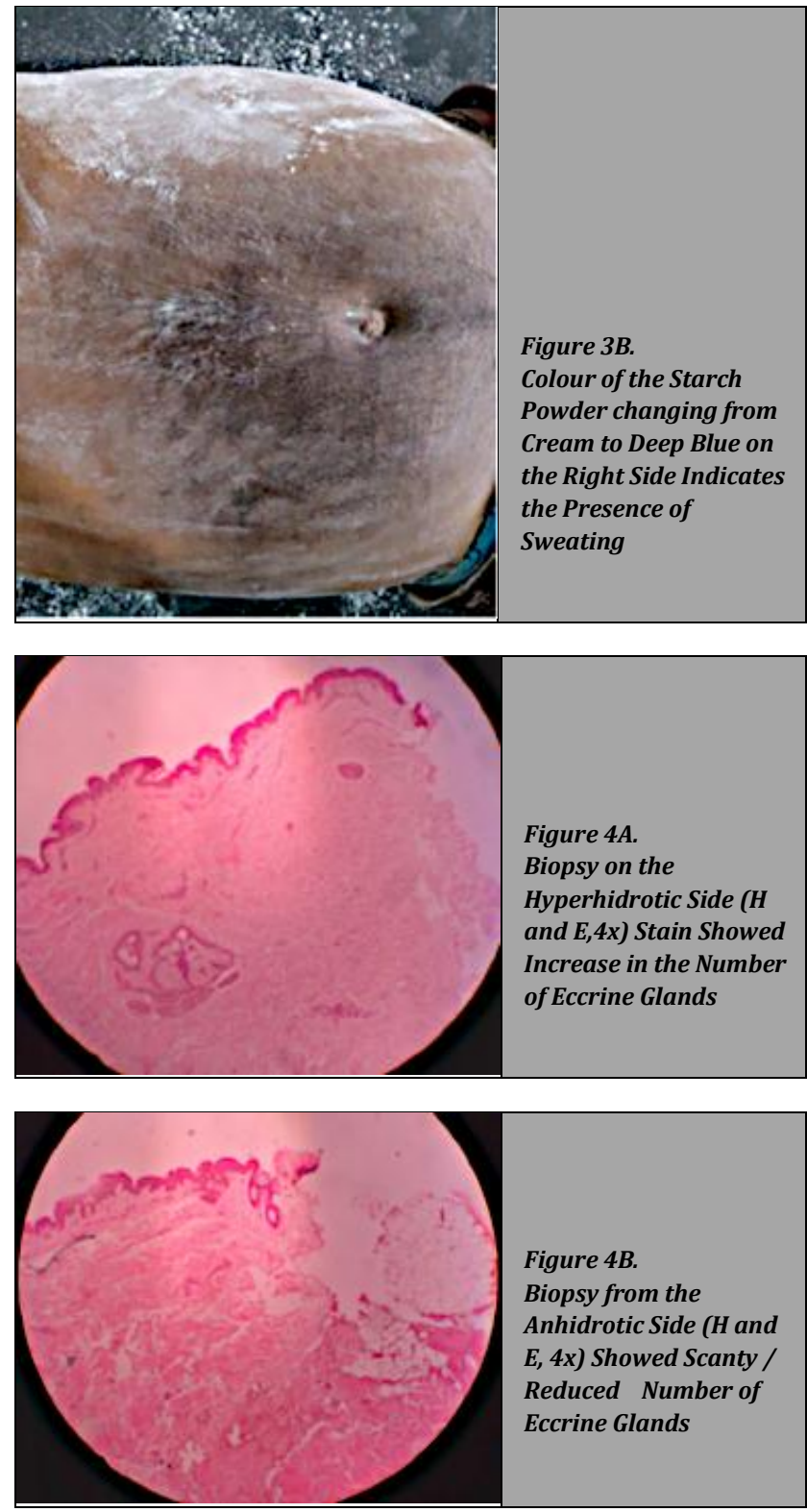

\section{DISCUSSION}

Ross syndrome is a rare entity that manifests typically with segmental hypohidrosis or anhidrosis with compensatory hyperhidrosis, areflexia and tonic pupil. ${ }^{3}$ Only about 40 cases have been discussed in the literature. ${ }^{4}$ Pathogenesis of this disorder is poorly understood but manifestations are because of damage to the peripheral autonomic system, ${ }^{5}$ loss of sweat is accounted by damage to the postganglionic sympathetic fibres that supply the sweat gland, ${ }^{6}$ absence of deep tendon reflexes can be accounted by damage to the dorsal root ganglia or spinal interneurons. ${ }^{7}$ Literature also suggests an autoimmune component to the progression of the disease but till date only handful of cases with Ross syndrome have been shown to have an antinuclear antibody test positive ${ }^{8}$. It is a benign disease with a progressive peripheral autonomic dysfunction with the typical age of presentation at mid-thirties with a female preponderance ${ }^{7}$ Our case fits the typical age but our patient is a 35 year old male we have ruled out Harlequin syndrome as our patient had pupillary abnormalities, patients with ross syndrome may show systemic signs of autonomic dysfunction but fortunately our patient had none, other causes of tonic pupil like diabetes mellitus, herpes, injuries, infections, Guillain barre syndrome, multiple sclerosis, syphilis, and tumours are excluded by history taking, physical examination and extensive investigations. We also ruled out the differentials of Holmes-Adie syndrome (Adie's tonic pupil, photophobia, absent knee and ankle jerks), Horner's syndrome (ptosis, miosis, loss of hemifacial sweating and enophthalmos), and hereditary sensory autonomic neuropathy (anhidrosis with the normal pupil). ${ }^{9}$ There is no effective treatment for this condition. Our patient responded partially to topical application of aluminium chloro hydrate $20 \%$ on to the sites of hyperhidrosis and is still visiting our hospital at regular intervals.

Financial or Other Competing Interests: None.

\section{REFERENCES}

[1] Shin RK, Galetta SL, Ting TY, et al. Ross syndrome plus: beyond horner, Holmes-Adie and harlequin. Neurology 2000; 55(12):1841-6.

[2] Sommer C, Lindenlaub T, Zillikens D, et al. Selective loss of cholinergic sudomotor fibres causes anhidrosis in Ross syndrome. Ann Neurol 2002; 52(2):247-50.

[3] Ballestero-Díez M, García-Río I, Dauden E, et al. Ross syndrome, an entity included within the spectrum of partial dysautonomic syndromes. J Eur Acad Dermatol Venereol 2005; 19(6):729-31.

[4] Nolano M, Provitera V, Perretti A, et al. Ross syndrome: a rare or a misknown disorder of thermoregulation? A skin innervation study on 12 subjects. Brain 2006; 129(Pt 8):2119-31.

[5] Luong MS, Jomir L, Labauge P, et al. Ross syndrome with sweating anomaly associated with Sjögren syndrome: an infrared thermo-graphic case study. Acta Derm Venereol 2011; 91(1):80-1.

[6] Agarwala MK, George L, Parmar H, et al. Ross syndrome: a case report and review of cases from India. Indian J Dermatol 2016; 61(3):348.

[7] Mullaaziz D, Kaptanoglu AF, Eker A. Hypohidrosis or hyperhidrosis? Ross syndrome. Dermatol Sinica 2016; 34(3):141-3.

[8] Vasudevan B, Sawhney MPS, Vishal S. Ross syndrome with ANA positivity: a clue to possible autoimmune origin and treatment with intravenous immunoglobulin. Indian J Dermatol 2010; 55(3):274-6.

[9] Sharma MK, Gupta S, Yadav S, et al. A rare case of Ross syndrome. Indian Dermatol Online J 2017; 8(5):370-2. 